\title{
Risk Propagation of Delayed Payment in Stakeholder Network of Large Hydropower Project Construction considering Risk Resistance and Mitigation
}

\author{
Yun Chen, ${ }^{1,2}$ Zhigen Hu $\mathbb{D}^{1,2}$ Quan Liu, ${ }^{1,2}$ and Maoyang Zhao ${ }^{3}$ \\ ${ }^{1}$ School of Water Resources and Hydropower Engineering, Wuhan University, Wuhan 430072, China \\ ${ }^{2}$ State Key Laboratory of Water Resources and Hydropower Engineering Science, Wuhan University, Wuhan 430072, China \\ ${ }^{3}$ Yalong River Hydropower Development Company, Ltd, Chengdu 610051, China \\ Correspondence should be addressed to Zhigen Hu; zhigenhu@whu.edu.cn
}

Received 23 March 2018; Accepted 5 June 2018; Published 5 July 2018

Academic Editor: Rosa M. Benito

Copyright (C) 2018 Yun Chen et al. This is an open access article distributed under the Creative Commons Attribution License, which permits unrestricted use, distribution, and reproduction in any medium, provided the original work is properly cited.

\begin{abstract}
Large hydropower project involves numerous stakeholders in the construction phase. The risk of delayed payment may escalate into an event of catastrophic economic loss through complex stakeholders' relationships. This paper builds a complex stakeholder network by collecting all contract prices in large hydropower project construction (LHPC) and proposes a novel mathematical model based on Cellular Automata Susceptible-Infected-Susceptible (CA-SIS) framework to analyze the risk propagation of delayed payment (RPDP). In the model, to approximate actual loss diffusion, risk-resisting and risk-mitigating abilities of stakeholders are combined, and relevance between risk mitigation and time is taken into account. The rationality and feasibility of the novel model are illustrated through its application to an actual LHPC. The simulation results include the following: RPDP presents three phases: risk first slightly propagates, risk then exponentially breaks out, and at last propagation consequence will reach a stable state related to stakeholders' risk-resisting ability closely; in respect of stakeholders' risk-mitigating ability and property of the network, RPDP range decreases with the increase of number of partners and homogeneity of contract price distribution; in respect of stakeholders' risk-resisting ability, RPDP range decreases with the decrease of number of partners. This research can serve as a powerful complement to analyze and control the delayed payment in LHPC.
\end{abstract}

\section{Introduction}

Large hydropower project requiring substantial investment and tremendous public resources belongs to the critical infrastructure engineering and has more profound impact on local communities and even a nation than general infrastructure engineering $[1,2]$. Because of the varied essence of construction business activity, various types of construction process, complex construction environment, and longtime construction [3], in large hydropower project construction (LHPC), stakeholders are widely exposed to a high degree of economic risk, including construction cost/duration overrun, delayed payment, changes in government regulation, poor performance of suppliers or manufacturers, and other situations [4-6]. The delayed payment has been generally recognized as the highest potential risk which drives down the productivity of the project and causes the project gridlock [7-9]. In addition, delay in payment is directly related to cash flow which is critical to each stakeholder $[10,11]$. When timeliness of contract price payment cannot be guaranteed, the net cash flow becomes negative, which prevents contractors to pay for materials, labor, and general overheads expended in the construction [12]. Moreover, it will lead to multiple risks connected with cost, schedule, quality, safety, and environment [13]. For enhancing overall operation benefit of LHPC, exploring the characteristic of risk of delayed payment and building quantitative model to evaluate its impact are very important.

Several previous works have studied the risk analysis and assessment in LHPC. Liu et al. [14] focused on the risks of schedule and cost in LHPC by utilizing the probability theory and Monte Carlo simulation method. Zhou et al. 
TABLE 1: Comparison between three epidemic models (SIR, SI, and SIS) from model description and propagation threshold.

\begin{tabular}{lcc}
\hline Model name & Model description & Propagation threshold \\
\hline SIR [38] & $\begin{array}{c}\text { The infected node is removed from the number of } \\
\text { susceptible nodes, as recovery or failure completely. }\end{array}$ & $\begin{array}{c}\text { There exists a threshold density of nodes. If the actual } \\
\text { density surpasses this threshold value, one (or more) } \\
\text { infected node will give rise to a spread. }\end{array}$ \\
\hline SI [39] & The infected node will be in permanently infected state. & $\begin{array}{c}\text { If susceptible probability is above the threshold, the } \\
\text { failure becomes persistent. Below it, the failure } \\
\text { exponentially dies out. }\end{array}$ \\
\hline SIS [39, 40] & The infected node has chance to vary from infected \\
state to susceptible state. & $\begin{array}{c}\text { When susceptible rate exceeds the threshold, the node } \\
\text { will be infected, while there also exists the threshold of } \\
\text { returning to susceptible state. }\end{array}$ \\
\hline
\end{tabular}

[15] analyzed interactive relationships among risk factors of human involved in LHPC and combined DEMATEL and ANP to single out important risk factors. Liu et al. [16] studied the probability of risk occurrence, potential consequence, and level of rockburst risk in the Jinping II hydropower station. To update the variation of new knowledge and early warnings, Bai et al. [17], Shalev et al. [18], Paltrinieri et al. [19], and Khan et al. [20] explored dynamic risk management and updated risk evaluation to lessen uncertainty, since any process is subject to constant evolution due to natural or human causes [20]. These studies provided valuable methods for analysis and assessment of risk of delayed payment in LHPC. Limitations of these researches inevitably focus on single perspective exploration, which did not consider overall connections of engineering components.

Owing to the complexity of LHPC in structure, context, organization, and technology [21, 22], a wide range of stakeholders at multiple level and from diverse backgrounds participate in the construction. The delayed payment triggered by interdependent stakeholders cannot be limited to two parties [23]. A motivating force to this improvement is that relationships among stakeholders are more appropriately viewed as complex network structure. Yang et al. [24], Li et al. [25], Wang et al. [26], Mok et al. [27], and Yu et al. [28] adopted the Social Network Analysis to construct a relationship between stakeholder and risk factor. They first conducted a thorough literature review to identify stakeholders and corresponding risk factors. A questionnaire was then designed to determine the connections among risk factors. At last, the relationships of stakeholders were built by cause-effect links among risk factors. However, this method becomes invalid when solely a type of risk factor is studied. In this paper, the risk of delayed payment is tightly associated with contract causes and price [4]. All contract prices among stakeholders are collected to build a stakeholder network, where nodes represent stakeholders and links stand for contractual relationships among them.

Although collaboration of interdependent stakeholders can enhance holistic and macroscopical operation of LHPC [29], once a payment problem starts to develop, it typically propagates small-scale financial burdens from one stakeholder to another through contract clauses and then escalates into an event of catastrophic economic loss [30]. For example, one 'upstream' stakeholder (e.g., Prime Contractor) might propagate economic risk to its numerous 'downstream' stakeholders (e.g., subcontractor). The contractor fails to make payment to subcontractors in time, resulting in cash flow difficulty of the subcontractor. Conversely, the 'downstream' stakeholders with risky state can also affect the 'upstream' stakeholder. Because of lacking capital, subcontractors have to delay the construction schedule. The phenomenon, which is called risk propagation of delayed payment (RPDP) in this research, brings great challenge to traditional risk management approaches due to dynamic process of propagation and diffusion. Thus, a new perspective of risk management is needed to dampen risk propagation among stakeholders in LHPC.

In the last decade, propagation of failure risk which is also called cascading failure is quite prevalent in physical networks, especially critical infrastructures, such as electric power networks [31,32], gas networks [33], oil networks [34], water supply networks [35], and transportation networks [36], while several differences in engineering mechanism between impersonality network and stakeholder network will lead to the risk analysis result being far from the reality. Note that cascading failure mechanisms in physical networks are captured by physics-based flow models, while RPDP is analyzed under probabilistic frameworks. Additionally, nodes representing stakeholders in the network have capability of risk resistance and mitigation [37]. The propagation procedure with these particular features is generally quantified by three epidemic propagation-based models, namely, SIR (Susceptible-Infected-Remove) [38], SI (Spreading of Infection) [39], and SIS (SusceptibleInfected-Susceptible) [39, 40]. The comparison of three models is represented in Table 1 . The other models, such as SIRS (Susceptible-Infected-Removed-Susceptible) [41], SEIR (Susceptible-Exposed-Infected-Removed) [42], and CA (Cellar Automaton) [43], are improved based on the three models. As a generalization of the propagation model, SIS is more appropriate to calculate the risk propagation in the stakeholder network. Stakeholders carrying the capability of risk resistance and mitigation have extremely similar feature with individual in SIS. Learning from Table 1, we can obtain that the threshold is a vital parameter in the propagation model. The threshold phenomenon does exist in the sense that risk starts to spread when propagation probability exceeds a critical value [39]. The fact that the 
TABLE 2: Contract prices between five stakeholders (Sup1, Sup8, CC20, CC22, and CC24).

\begin{tabular}{lccccc}
\hline & Sup1 & Sup8 & CC20 & CC22 & CC24 \\
\hline Sup1 & 0.00 & 0.00 & 6.87 & 0.37 \\
Sup8 & 0.00 & 0.00 & 218.85 & 398.98 & 0.00 \\
CC20 & 6.87 & 218.85 & 0.00 & 0.00 & 0.00 \\
CC22 & 12.52 & 398.98 & 0.00 & 0.00 \\
CC24 & 0.37 & 11.81 & 0.00 & 0.00 \\
\hline
\end{tabular}

Note. Unit of contract price is ten thousand RMB. This table is symmetric because of bidirectional property of contract, where 0.00 represents no contractual relationship.

value of threshold is related to the degree in complex network has been proved [44, 45]. However, these studies did not involve the relevance between risk mitigation and time. Thus, this paper proposes an improved model based on SIS and $\mathrm{CA}$, wherein the relation between time factor and riskmitigating probability and the threshold of risk mitigation are put forward to develop the SIS.

The rest of the paper is organized as follows: Section 2 presents the establishment process of stakeholder network of hydropower construction project; Section 3 proposes a novel model of RPDP; Section 4 takes a real LHPC as example to simulate the procedure of RPDP, and the parameters of the model are adjusted to demonstrate the rationality and feasibility of the improved model and analyze the propagation results of RPDP.

\section{Generation Stakeholder Network}

2.1. Identification of Stakeholders. Large-scale hydropower projects are decomposed into a number of subprojects, requiring the involvement and participation of many interdependent stakeholders. The complex interrelationships among them are more appropriately viewed as a complex network. In the network building process, the first step is to identify the nodes representing the stakeholders in complex network. The stakeholders indicate any individuals and organizations who actively participate in the project or whose interests are positively or negatively affected by project execution, such as owners, designers, prime contractors, subcontractors, supervisors, and government departments. During the long period of construction, these project stakeholders are not constant, because with the advancement of construction schedule, the number of stakeholders shows a state of flux that increases at first and then decreases generally. It is noted that the set of project stakeholders is identified at a particular point in time. Yangfanggou hydropower station is the first large-scale hydropower engineering adopting the project management pattern of Design-Build (DB). The Prime Contractor was formed by Huadong Engineering Corporation Limited (designer) and Sinohydro Bureau 7 Co., Ltd (prime construction contractor). We collected all stakeholders of Yangfanggou hydropower station in October 2016 to identify the set of nodes of the stakeholder network.

2.2. Identification Relationships among Stakeholders. Because of LHPC largely depending on the collaboration of multiple stakeholders throughout all project processes [29], the relationship between stakeholders is varied and intricate, such as cooperation, supervision, affiliation, and competition. Payment refers to the sum of money paid to contractors after completing the work promised by them under contracts [46]. It represents a relationship between stakeholders in the form of payment provision of a contract [47]. Thus, the contractual relationship closely links two stakeholders, which is a bridge between them. Conventional studies usually used 0 to indicate independence and 1 to express interdependence. According to definition of degree centrality of node, the quantity of adjacent nodes is applied to denote the importance of the node. However, in actual construction, it is not reasonable to use the quantity of partners to evaluate the importance of a stakeholder. Especially in prime contract project, Owner has only one partner that is Prime Contractor. However, the status of the Owner surely cannot be ignored. Therefore, all contract prices among stakeholders of Yangfanggou hydropower station are collected to indicate the relationship's weight. Moreover, the contract is a mutually binding agreement, meaning that relationship is bidirectional. In summary, the relationship between stakeholders is shown as bidirectional and weighted contractual connection. Table 2 provides an example of weighted adjacency matrix to illustrate the relationships, where the first column and the first row represent five stakeholders (Sup1, Sup8, CC20, CC22, and CC24) in Yangfanggou hydropower station, and the values in the cells refer to contract prices between two stakeholders. For example, 6.87 denotes that the contract price between Sup1 and CC20 is 68,700 RMB. Because of bidirectional property of contract, the adjacent matrix of the example is symmetric.

2.3. Visualization of Stakeholder Network. Once the nodes (i.e., stakeholders) and edges (i.e., relationships) are identified, stakeholders of Yangfanggou hydropower station in October 2016 can be modeled as a complex stakeholder network. A bidirectional and weighted $G=(N, W)$ is used to describe the stakeholder network, where the identified stakeholders are mapped into $N$ nodes connected by $W$ bidirectional and weighted edges. Based on Table 2, a part of stakeholder network is visualized in Figure 1. Tiny squares represent the nodes: Sup1, Sup8, CC20, CC22, and CC24. Straight-line segments indicate edges of the network. The length of line has no significance, and the numbers on the different straight-line segments represent edges' weights (i.e., 
TABLE 3: Stakeholders, contractual relationships, and contract prices in Yangfanggou hydropower station are represented as nodes, edges, and weights of edges, respectively.

\begin{tabular}{|c|c|}
\hline $\begin{array}{l}\text { Nodes/Edges/Weights } \\
\text { of edges }\end{array}$ & $\begin{array}{c}\text { Stakeholders, contractual relationships, and contract prices } \\
\text { in Yangfanggou hydropower station }\end{array}$ \\
\hline Owner & Hydropower Project Investor (Yalong River Hydropower Development Company, Ltd) \\
\hline PC & $\begin{array}{c}\text { Prime Contractor formed by Designer and Prime Construction Contractor (Huadong } \\
\text { Engineering Corporation Limited and Sinohydro Bureau } 7 \text { Co., Ltd) }\end{array}$ \\
\hline QI1 & Department 1 of Quality Inspection \\
\hline QI2 & Department 2 of Quality Inspection \\
\hline PS & Prime Supervisor \\
\hline S1-S6 & Sub-supervisor $1 \sim$ Sub-supervisor 6 \\
\hline $\mathrm{PD}$ & Prime Designer \\
\hline $\mathrm{D} 1 \sim \mathrm{D} 5$ & Designer $1 \sim$ Designer 5 \\
\hline PCC & Prime Construction Contractor \\
\hline $\mathrm{CC} 1 \sim \mathrm{CC} 27$ & Construction Contractor $1 \sim$ Construction Contractor 27 \\
\hline Sup1 Sup19 & Supplier $1 \sim$ Supplier 19 \\
\hline Edges & Contractual Relationships among Stakeholders \\
\hline Weights of edges & Contract Prices among Stakeholders (/ten thousand RMB) \\
\hline
\end{tabular}

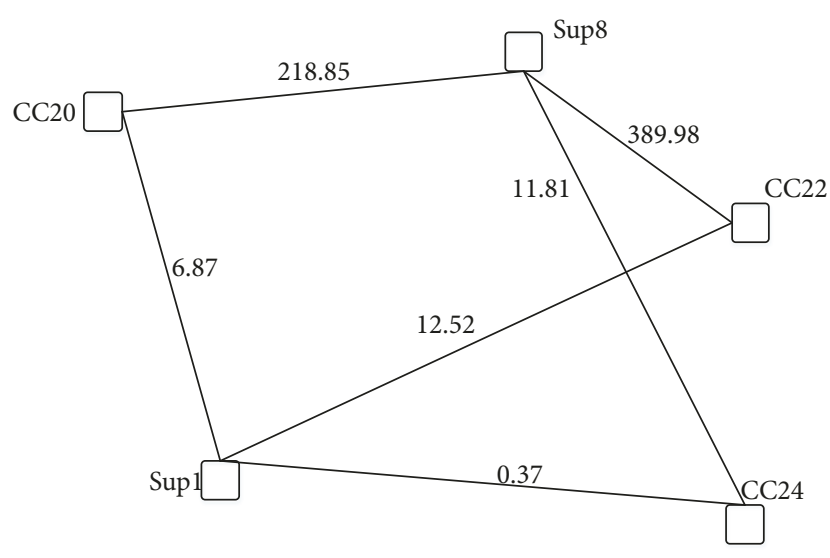

FIgURE 1: A part of stakeholder network of construction project in Yangfanggou hydropower station (SNCPYHS). Sup1, Sup8, CC20, CC22, and CC24 represent the stakeholders. Edges represent contractual relationships and values on them are the contract prices in ten thousand RMB.

contract price). The contract prices between Sup1 and Sup8, CC20 and CC22, and C22 and CC24 are equal to 0.00, meaning no link between two nodes.

To complete the stakeholder network of Yangfanggou hydropower station, whole adjacent matrix in Excel spreadsheet, containing 64 stakeholders and contract prices among them, is exported to UCINET 6 for Windows 6.212. Thereafter, stakeholder network of construction project in Yangfanggou hydropower station (SNCPYHS) is visualized by using NetDraw 2.084 as shown in Figure 2. The interpretations of each node and edge are shown in Table 3 . The whole SNCPYHS which includes all stakeholders and contract prices is provided in Supplementary Materials (available here).

\section{Modeling the Risk Propagation}

3.1. The Description of RPDP Process. We suppose that, in a central-position of SNCPYHS, the Owner makes a payment to the Prime Contractor. Thereafter, the Prime Contractor pays the amount to its subcontractors. If delayed payment happens, the risk will cause a cascading propagation. Upstream stakeholder transfers the irregular cash flow to downstream stakeholders, which makes them unable to maintain normal capital operation. The 'downstream' stakeholders in turn affect 'upstream' stakeholder through schedule delay, poor quality, and safety accidents. In the procedure of RPDP, the delayed payment risk that a stakeholder suffered accumulates with increase of quantity of lossmaking stakeholders cooperating with it. When probability of risk occurrence exceeds the risk-resisting ability, the state of economic loss will appear. Moreover, each stakeholder has the ability to eliminate risk by capital pooling, management, and operation. The loss-making stakeholders can regain original state with a probability. Considering the stakeholder's response to the delayed payment, the frame of SusceptibleInfected-Susceptible (SIS) is used for reference [48]. In SIS model, nodes shift between two states: susceptible and infective state. When a susceptible node transfers to infective state with a probability $\lambda$, it will infect its neighbors (if there is any). Meanwhile, the infective nodes have a probability $\beta$ to recover to susceptible state or stay in the original infective state with a probability $1-\beta$. Figure 3 clearly presents a stakeholder's variation between two states including risky state regarded as economic loss and normal state. In order to further illustrate the propagation process in the stakeholder network, two conceptual stakeholder networks are presented in Figure 4.

3.2. The Model of RPDP Process. Before we begin with the construction of the model, some assumptions must be made. 


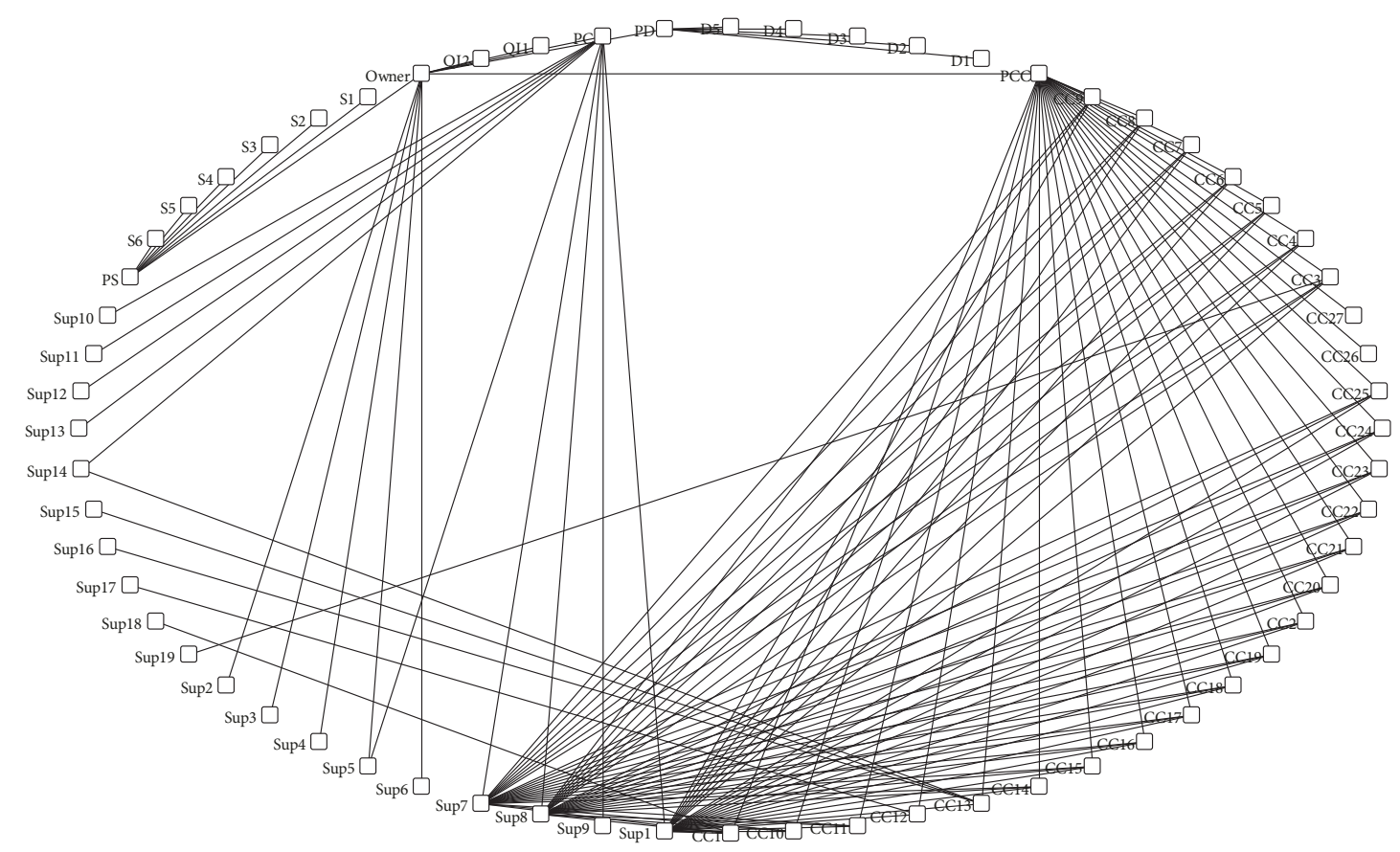

FIGURE 2: Complete stakeholder network of construction project in Yangfanggou hydropower station (SNCPYHS). Nodes (Owner, PC, QI1, etc.) represent all stakeholders. Edges represent contractual relationships between them.

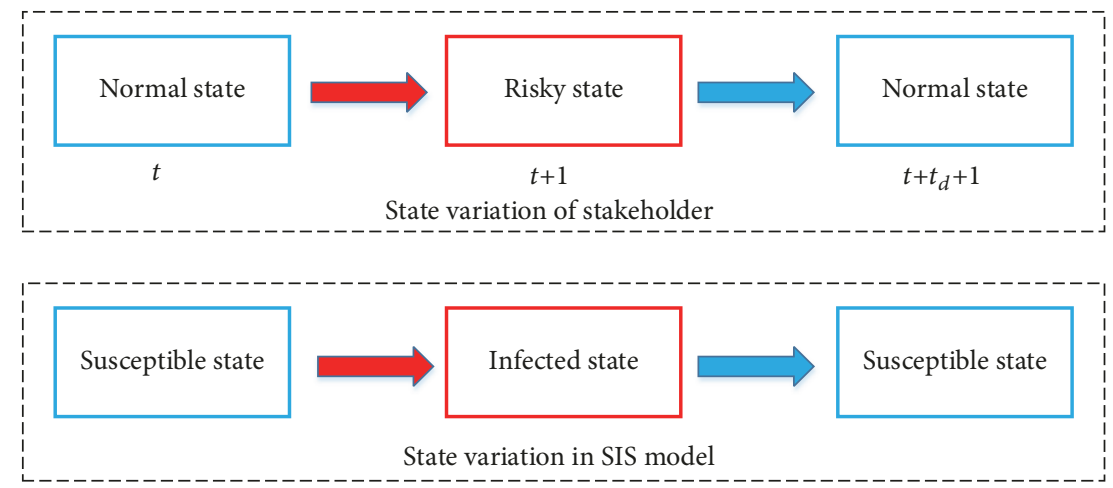

FIGURE 3: Variation process of stakeholder's state and state variation process in SIS model. A stakeholder may be transferred from normal state at time $t$ to risky state at time $t+1$ and can recover to normal state after time interval $t_{d}$. Normal state of the stakeholder is similar to susceptible state in SIS model. Risky state of the stakeholder resembles infected state in SIS model.

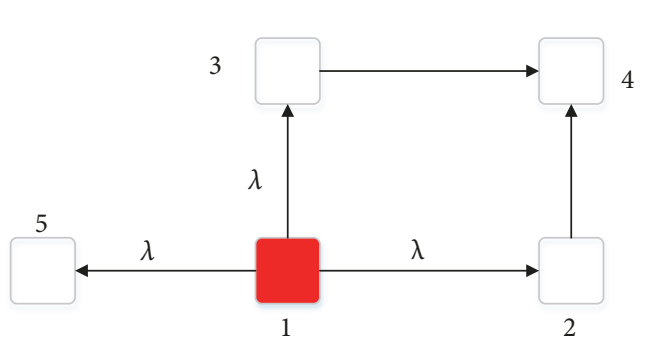

(a)

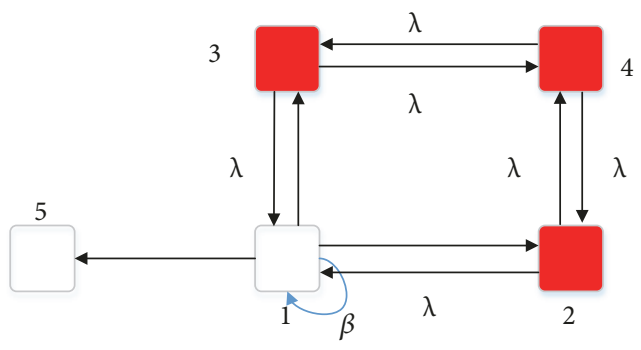

(b)

FIGURE 4: Process of risk propagation in conceptual stakeholder network. (a) Stakeholder 1, as risk propagation source, propagates the risk to its neighbor stakeholders 2, 3, and 5 with probability $\lambda$, respectively. (b) Because the risk-resisting abilities of stakeholders 2 and 3 are smaller than $\lambda$, their normal states are transferred to risky state. With increment of quantity of loss-making stakeholders connected with stakeholder 4 , its state is varied from normal to risky state. Stakeholder 1 has probability $\beta$ to recover to the normal state; meanwhile it is also affected by stakeholders 2 and 3 with $\lambda$. 
The financial information of company is confidential to the public, which adds great burden of basic data collection. Additionally, numerous external and internal risk factors lead to computational complexity and inaccuracy in risk probability. All stakeholders with equal probability of risk mitigation are assumed at the beginning, and then let probability vary in a certain range to analyze multiple results. Assuming that all stakeholders have only two states, risky state regarded as economic loss and normal state, lessens the complicacy of the model construction. It must be noted that one stakeholder's state is not solely restricted to binary. Both intermediate state and multistate can be also described according to risky extent [49-51]. As RPDP is based on the structure of the stakeholder network, it is assumed that the risk propagates along the contractual relationship (i.e., the node is only triggered by adjacent node). Assuming that stakeholders are moved out of the construction project as economic loss appears does not conform to reality, because stakeholders will not terminate contractual relationship until they complete the part of the project that they are responsible for.

Taking into account all of these possible concerns, we should make several assumptions as follows:

(1) All stakeholders have equal probability of risk mitigation.

(2) The states of all stakeholders have two aspects: the state of economic loss is 1 and the normal state is 0 .

(3) The stakeholder is only affected by its direct partners.

(4) When economic loss situation occurs, they will not terminate the contractual relationship.

Cellular Automata (CA) are adopted to describe a complex discrete system consisting of a large number of connected cells and to simulate dynamical evolution of propagation process [43]. RPDP is a complex, dynamic, and discrete process in space and time through the previous analysis. Therefore, in order to mathematically describe how risk of delayed payment propagates in the stakeholder network, Cellular Automata Susceptible-Infected-Susceptible (CA-SIS) model which combines the CA and SIS is introduced to quantitate RPDP. The CA-SIS model is defined by $(C, Q, V, F)$.

Cellular Space C. Every stakeholder is considered as a cell. The $C$ can be represented by whole stakeholders $N$ :

$$
C=N \text {. }
$$

Set of State Q. is the finite state set, which is a set of the economic state of stakeholders at each time step. The normal state is indicated by 1 and risky state is indicated by $0 . S_{i, t}$ is used to denote $i$ th stakeholder's state at time $t$ :

$$
S_{i, t}= \begin{cases}0, & \text { risky state; } \\ 1, & \text { normal state }\end{cases}
$$

Cellular Neighborhood $V$. Let $V=\left[w_{i j}\right]_{N \times N}$ be the adjacency matrix with weight. The contractual relationship between stakeholders can be indicated by the weighted adjacency matrix:

$$
\begin{aligned}
& V_{i j} \\
& = \begin{cases}w_{i j}, & i \text { th node and } j \text { th node are connected; } \\
0, & i \text { th node and } j \text { th node are not connected. }\end{cases}
\end{aligned}
$$

State transition function $F$ consists of two rules as follows: (1) Each stakeholder has risk-resisting ability which is closely related to their own capability and partners' impact. For calculating the risk-resisting threshold, Zhang et al. [52] proposed a method combining the node's degree and degrees of the adjacent nodes. This is because the node's degree is one of the most common and also the simplest indicators for describing the node's property [52]. To be more specific, the greater a node's degree and degrees of its adjacent nodes are, the higher probability of facing risk is, the higher riskresisting ability stakeholder has. The risk-resisting ability of $i$ th stakeholder is calculated based on three conditions: (1) the degree of $i$ th node; (2) the degree of its adjacent node; (3) the average impact. However, edges representing contract prices in the stakeholder network are different from the interactions between nodes in unweighted graph. The stakeholder with the largest contract price, for instance, is the Owner whose contract price is 8.5118 billion RMB, while the smallest one is the Supplier 18 whose contract price is $58,630 \mathrm{RMB}$. The enormous discrepancy between two values of contract price greatly expands the disparity of nodes' degrees, which causes extremely unbalance of risk-resisting thresholds. To avoid the large gap, the equation of the risk-resisting threshold is improved as follows:

$$
\gamma_{\lambda i}=\frac{D_{i}+\sum_{m \in \Gamma_{i}} D_{m}}{\max \left\{\left(D_{j}+\sum_{l \in \Gamma_{j}} D_{j} \mid j=1,2, \cdots, N\right)\right\}}
$$

where $\gamma_{\lambda i}$ is the risk-resisting threshold of $i$ th stakeholder; the degree of node $i$ is $D_{i}=\sum_{m \in \Gamma_{i}} w_{m} ; \Gamma_{i}$ is the set of partners of $i$ th stakeholder; and $\Gamma_{j}$ is the set of partners of $j$ th stakeholder.

We use $S_{i, t}$ and $S_{i, t+1}$ to indicate $i$ th stakeholder's state at time $t$ and $t+1$. At time $t+1 S_{i, t+1}$ depends on $S_{i, t}$ and states of $i$ th stakeholder's partners. If the stakeholder makes a loss at the time $t$, it will keep original state without control measure; otherwise the probability of risk occurrence increases with increment of quantity of the loss-making partners. This procedure is quantified as below:

$$
S_{i, t+1}=S_{i, t}+\overline{S_{i, t}} f\left(\gamma_{\lambda i}\right)
$$

where $S_{i, t}=0$, if the probability of risk occurrence is less than the risk-resisting threshold; otherwise, $S_{i, t}=1 ; \overline{S_{i, t}}$ represents the opposite of $S_{i, t}$. Namely, if $S_{i, t}=1, \overline{S_{i, t}}=0$; otherwise, $\overline{S_{i, t}}=1$.

$f\left(\gamma_{\lambda_{i}}\right)$, as a propagation indicator, is used to indicate the variation of $i$ th stakeholder's state at time $t$ after being affected by its loss-making partners. Thus, it is determined by the quantity of partners with loss state. If the sum of loss probabilities of risky partners exceeds the risk-resisting 
threshold, the stakeholder will vary from normal state to risky state. The conversion procedure can be presented as follows:

$$
f\left(\gamma_{\lambda i}\right)= \begin{cases}0, & 1-\prod_{j \in \Gamma}\left(1-\lambda_{j}\right)^{a_{i j} S_{i, t}} \leq \gamma_{\lambda i} \\ 1, & 1-\prod_{j \in \Gamma}\left(1-\lambda_{j}\right)^{a_{i j} S_{i, t}}>\gamma_{\lambda i}\end{cases}
$$

where $a_{i j}=1$, if $i$ and $j$ are directly connected, and $a_{i j}=0$, if $i$ and $j$ have no relation; $\lambda_{j}$ indicates the probability of risk occurrence of $j$ th stakeholder who is the partner of $i$ th stakeholder; and $1-\prod_{j \in \Gamma}\left(1-\lambda_{j}\right)^{a_{i j} S_{i, t}}$ means that probability of risk occurrence $i$ th stakeholder gradually increases with growth of the number of partners. When $1-\prod_{j \in \Gamma}(1-$ $\left.\lambda_{j}\right)^{a_{i j} S_{i, t}} \leq \gamma_{\lambda}$, ith stakeholder cannot be affected; otherwise, $i$ th stakeholder's state will be converted. We simply assume that probability of risk occurrence of initial loss-making stakeholder is $(1 / N) \sum_{i=1}^{N} \gamma_{\lambda i}$ and then change it in a certain range to analyze risk propagation.

(2) This rule represents a transformation of the risky state of stakeholders after a certain period of time. Each stakeholder has the ability to eliminate existing risk. Thus, except for the risk-resisting ability, risk-mitigating ability should be an indispensable factor. After the period of time $t_{d}$, $i$ th stakeholder has a chance to convert from risky state to normal state with $1-\beta_{i}$ probability, if it was in risky state at time $t+1$. On the contrary, it will maintain normal state and be continually affected by $1-\prod_{j \in \Gamma}\left(1-\lambda_{j}\right)^{a_{i j} S_{i, t}}$, if it was not in risky state at time $t+1$. The rule is shown as follows:

$$
S_{i, t+t_{d}+1}= \begin{cases}S_{i, t+1} f\left(\gamma_{\beta_{i}}\right), & S_{i, t+1}=1 \\ S_{i, t+t_{d}}+\overline{S_{i, t+t_{d}}} f\left(\gamma_{\lambda i}\right), & S_{i, t+1}=0\end{cases}
$$

where $S_{i, t+1}, S_{i, t+t_{d}}$, and $S_{i, t+t_{d}+1}$, respectively, represent the states of $i$ th stakeholder at time $t+1, t+t_{d}$, and $t+t_{d}+1$. Additionally, as time goes on, the probability without recovering from economic loss is diminished under risk mitigation. $f\left(\gamma_{\beta_{i}}\right)$ is another propagation indicator to describe the state change of $i$ th stakeholder after time interval $t_{d}$, which is shown as follows:

$$
f\left(\gamma_{\beta i}\right)= \begin{cases}0, & \frac{\beta_{i}}{t_{d}} \leq \gamma_{\beta i} \\ 1, & \frac{\beta_{i}}{t_{d}}>\gamma_{\beta i}\end{cases}
$$

where $\gamma_{\beta i}$ represents the risk-mitigating ability; $\beta_{i}$ indicates the probability that loss-making stakeholder cannot recover from risky state; and $\beta_{i} / t_{d}$ is used to express a connection between time and probability without recovery. When $\gamma_{\beta i}$ is bigger than $\beta_{i} / t_{d}$, the risky state can be converted to normal; otherwise, the stakeholder sustains previous state and is continually affected by its risky partners. In the realworld, the risk-mitigating ability connected with several factors is too complicated to accurately calculate. To simplify the simulation of risk propagation, the probability without recovery is assumed as $(1 / N) \sum_{i=1}^{N} \gamma_{\beta i}$. In Section 4 , it will be adjusted in a certain range and compared with probability of risk occurrence.

The threshold $\gamma_{\beta}$ representing the risk-mitigating ability greatly depends on a stakeholder's status and enterprise scale which tightly are related to the importance and impact of a stakeholder in the whole project. Namely, if the stakeholder's importance is greater, its risk-mitigating ability will be accordingly high. Thus, assuming breaking a stakeholder's connections with all partners is used to observe its impact of the whole stakeholder network. Wang et al. [53] proposed a method to compute a node's function level which represents the node's importance after moving it, where sum of edges' values of the whole network can be computed by $F=\sum_{i=1}^{N} \sum_{j=1}^{N} w_{i j}$. After breaking all $k$ th stakeholder's connections with its partners, the values of remnant edges are calculated as follows:

$$
\begin{aligned}
F^{\prime}(k)= & \sum_{i=1}^{k}\left(\sum_{j=1}^{k} w_{i j}+\sum_{j=k+1}^{N} w_{i j}\right) \\
& +\sum_{i=k+1}^{N}\left(\sum_{j=1}^{k} w_{i j}+\sum_{j=k+1}^{N} w_{i j}\right)
\end{aligned}
$$

where $k$ represents a stakeholder moved. The stakeholder's risk-mitigating threshold $\gamma_{\beta}$ is presented as follows:

$$
\gamma_{\beta}=\frac{\left(F-F^{\prime}(k)\right)}{F} \text {. }
$$

At last, in order to measure the consequence caused by RPDP in the stakeholder network, the proportion of lossmaking stakeholders at the end of time $t$ is defined by $I(t)$. The equation is shown as follows:

$$
I(t)=\left(\frac{1}{N}\right) \sum_{i=1}^{N} S_{i, t}
$$

It can dynamically express the evolutionary procedure of RPDP. When the proportion of loss-making stakeholders $I$ is equal to 1 , it signifies that the all stakeholders have been in risky state.

\section{Simulation Results Discussion and Analysis}

In this section, SNCPYHS introduced in Section 2 is taken as an example to demonstrate the rationality and feasibility of the improved model and analyze RPDP through MATLAB simulation. The codes of MATLAB simulation are provided in Supplementary Materials. We assume that because of external or internal causes (e.g., global financial crisis or internal management problems), the Owner, as initial loss-making stakeholder, cannot make payment in time. First, several vital model parameters, including time interval, probability of risk occurrence, and probability without recovery, are deeply analyzed under numerical simulation. Second, whether RPDP considers risk mitigation or not will be compared to find which stakeholders have stronger abilities of risk resistance 


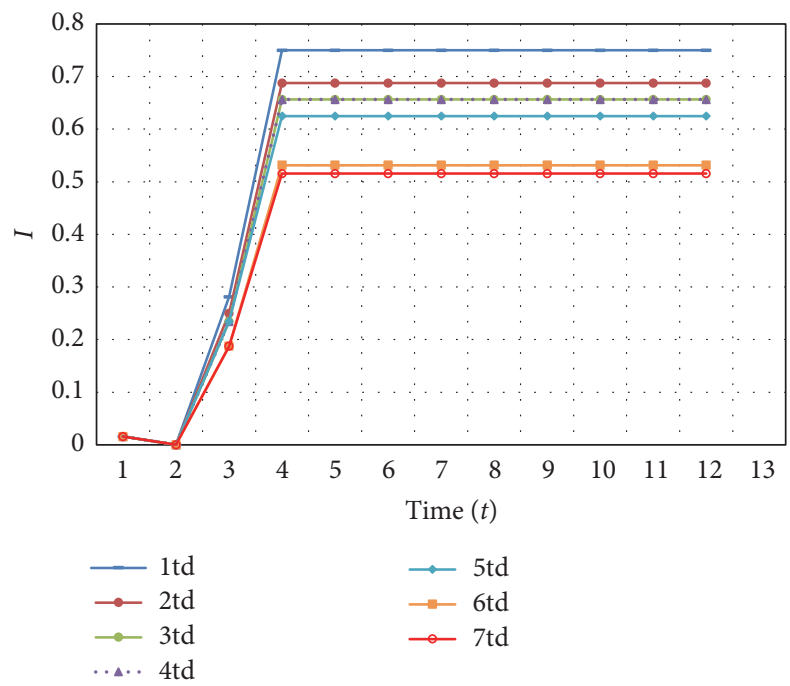

FIGURE 5: Variation of loss-making stakeholders proportion $(I)$ with time $(t)$ under time interval $\left(t_{d}\right)$ from 1 to 7 . One of curves reflects the variation of $I$ with $t$. In view of all curves, variation trend of $I$ curve with variation of $t_{d}$ can be compared.

and recovery and analyze their properties. Last but not least, a random stakeholder network is introduced to contrast the property of risk propagation of SNCPYHS from macroscopic perspective.

4.1. Results of RPDP under Changing of Parameters in the Model. Time interval, probability of risk occurrence, and probability without recovery are adjusted to prove the rationality of the improved model. The time interval $\left(t_{d}\right)$ related to extent of recovery is a critical factor in the model. It is varied from 1 to 7 for obtaining different results of RPDP.

Result in Figure 5 reflects the changing of $I$ curve with variation of $t_{d}$ from 1 to 7 . We can observe that RPDP suddenly breaks out from time 2 to time 4 and it will finally maintain at a stable value $I *$. For example, when $t_{d}=2$, the value of $I$ soars from 0.0000 at time 2 to 0.6875 at time 4 and stabilizes at 0.6875 at last. The gradual decline of $I$ curve is clear as $t_{d}$ grows. For instance, when $t_{d}=1,2,3,4,5,6$, and 7 , the values of $I$ are $0.2813,0.2500,0.2344,0.2344,0.2344,0.1875$, and 0.1875 at time 3 , wherein $t_{d}=1$ means the RPDP without considering time factor. The stable values $I *$ (i.e., values of $I$ at time $4 \sim 12$ ) are $0.7500,0.6875,0.6563,0.6563,0.6250,0.5313$, and 0.5156 , respectively. This is because the opportunity of recovery increases with time prolongation. In other words, the longer time interval is, the more stakeholders vary from risky state to normal state. The phenomenon verifies the rationality of the model which combines time and riskmitigating ability.

Figure 5 displays the three phases of RPDP: (1) risk first slightly propagates; (2) risk then breaks out; (3) in last phase, value of $I$ will converge to a stable value $I *$. Therefore, we use $I *$ to indicate ultimate consequence of risk propagation. In previous simulation, the probabilities of risk occurrence and mitigation (1-probability without recovery) are assumed to be only correlated with two types of thresholds, while risk has

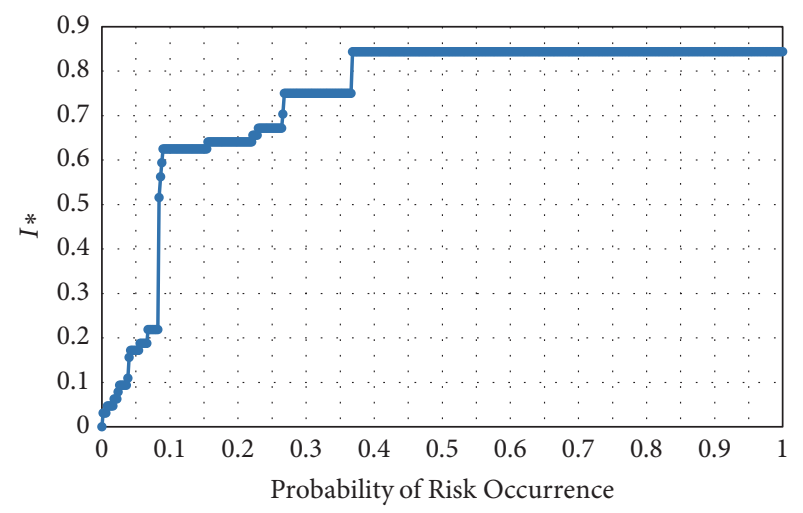

FIGURE 6: Variation process of ultimate stable value $(I *)$ with increase of probability of risk occurrence. The $I *$ is an ultimate stable value of loss-making stakeholders proportion $(I)$. The probability of risk occurrence is increased from 0 to 1 .

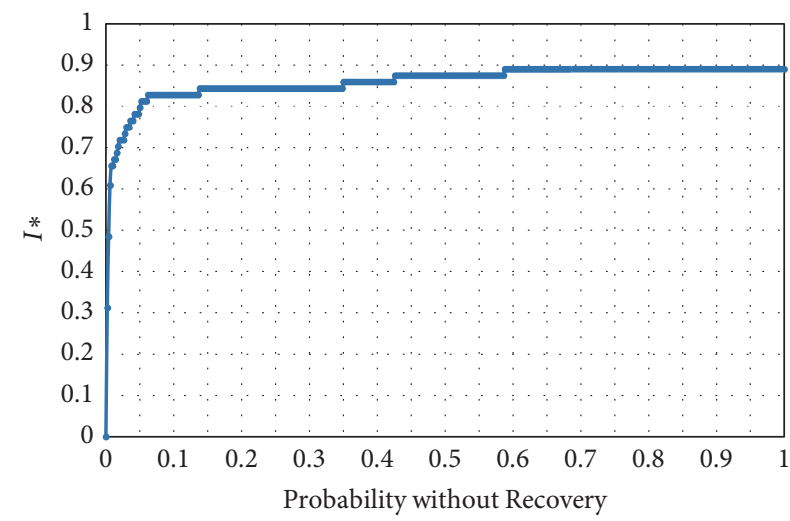

FIgURE 7: Variation process of ultimate stable value $(I *)$ with increase of probability without recovery. The $I *$ is an ultimate stable value of loss-making stakeholders proportion $(I)$. The probability without recovery is increased from 0 to 1 .

dynamic property affected by various aspects. Thus, when $t_{d}$ $=1$, the two risk probabilities are increased at the growth rate 0.0020 to represent the variation of $I *$ values, which is seen in Figures 6 and 7.

In Figure 6, there is a steep rise when the probability of risk occurrence increases to a certain value, 0.0820 . Above it, the proportion of loss-making stakeholders exponentially increases. Below it, the speed of growth of $I *$ is relatively slow. As can be seen in Figure 7, risky states of all stakeholders completely recover until probability of risk mitigation (i.e., 1-probability without recovery) increases to a certain value, 0.9400 . Above it, the most of stakeholders with risky state can recover. Apparently, the two values are critical thresholds for risk propagation. The increase of $I *$ with variation of two kinds of probability can reflect the stakeholder's sensibility to RPDP. From Figures 6 and 7, the impact of a stakeholder's risk-resisting ability on ultimate stable state is more sensitive than risk-mitigating ability.

The above-mentioned analysis results are obtained under change of one probability. Figure 8 presents interactive effect of the two probabilities at the growth rate 0.0020 . The 


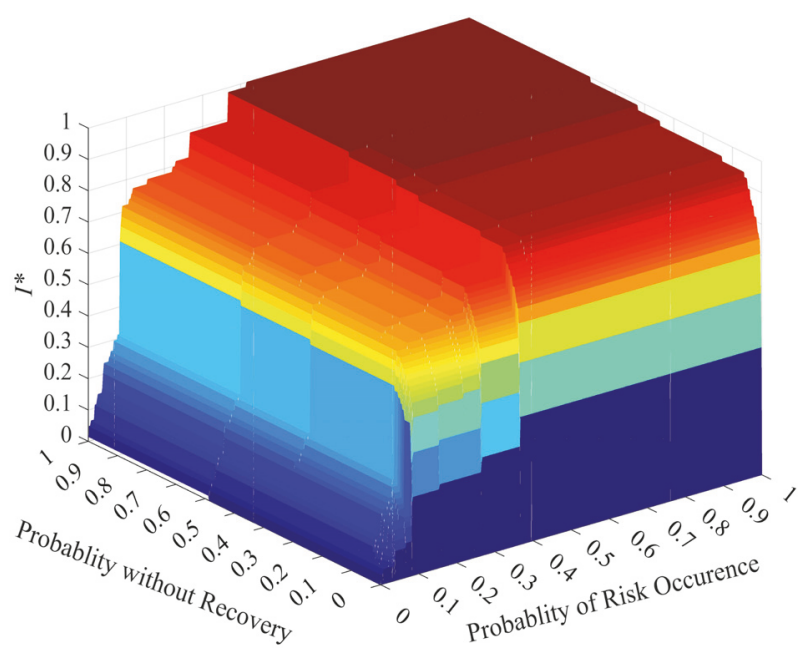

FIGURE 8: Variation process of ultimate stable value $(I *)$ with simultaneous increases of probability without recovery and probability of risk occurrence. The $I *$ is an ultimate stable value of lossmaking stakeholders proportion (I). Two probabilities simultaneously increase from 0 to 1 .

interactive ranges of the two probabilities are $[0,0.4140]$ and $[0,0.0620]$, respectively. When the probability of risk occurrence exceeds 0.4140 , it cannot affect changing trend of $I *$ values with the increase of probability of risk mitigation. When the probability of risk mitigation is above 0.0620 , the changing trend of $I *$ values almost will not be disturbed with variation of probability of risk occurrence. The phenomenon implies a consistent conclusion with abovementioned results.

4.2. Results of RPDP considering Risk Mitigation. RPDP with and without risk mitigation are compared when $t_{d}=1$ and shown in Figures 9 and 10. The aim is to explore common properties of the stakeholders with strong risk-mitigating and risk-resisting abilities from micro-perspective. Figure 9 contrasts the values of $I$ under the two situations. Figure 10 further visualizes the procedures which display the variation of stakeholders' states before getting stable value $I *$, where (a-1), (a-2), (a-3), and (a-4) belong to diffusional situation without risk mitigation from time 1 to 4 and (b-1), (b-2), (b-3), and (b-4) indicate diffusional situation with risk mitigation from time 1 to 4 . The red nodes in the figures represent loss-making stakeholders and the white nodes denote normal stakeholders. Figure 10 also provides useful information to understand the process of RPDP.

Figure 9 clearly suggests that the $I$ curve without risk mitigation is higher than the $I$ curve with risk mitigation at any time. For example, when $t=2,3$, and 4 , the values of $I$ are $0.1563,0.3281$, and 0.8906 under RPDP without risk mitigation, but are $0.0000,0.2813$, and 0.7500 when RPDP considers risk mitigation. This is because some stakeholders can convert into normal state after a certain period of time. The simulation result is accordant with the earlier conclusion that the stability of network is generally enhanced under recovery strategy compared with that under no recovery

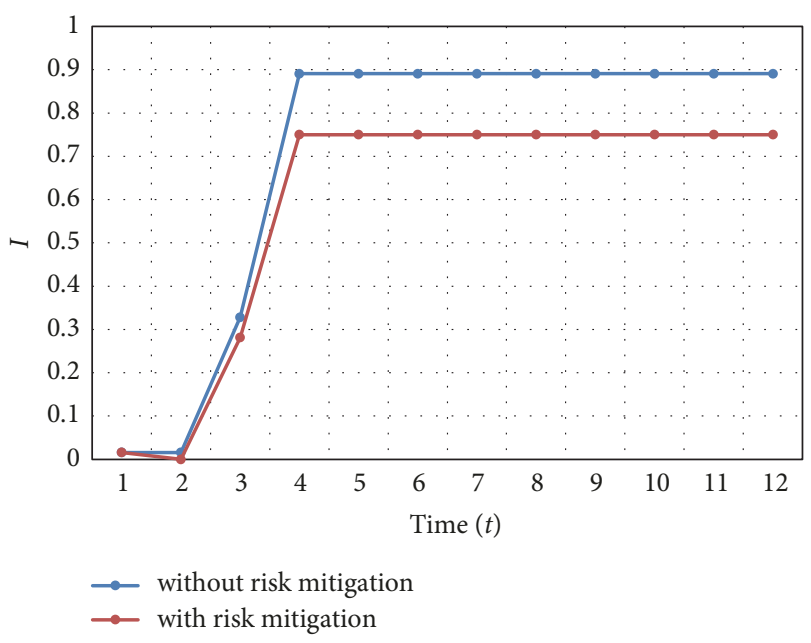

FIGURE 9: Variation of loss-making stakeholders proportion $(I)$ with time $(t)$ under situations with and without risk mitigation. One of curves reflects the variation of $I$ with $t$. In view of two curves, difference between $I$ curves with and without risk mitigation can be compared.

strategy [54], proving the feasibility of the model considering risk mitigation. It is noteworthy that, at time 2 , there is an inflection point in the $I$ curve with risk mitigation. At this time, the Owner, which was in the risky state, has recovered, and other stakeholders have not yet been converted. However, it does not mean that the Owner's negative effect on the other stakeholders has disappeared. Potential risk of delayed payment still exists. Thus, after time 2 , the risk continues to propagate to downstream stakeholders.

The comparison in Figure 10 displays that the Owner is the first stakeholder to manifest the risk-mitigating ability at time 2 followed by D3 and CC13 at time 3. Then, PCC, Sup7, Sup8, PC, PS, and PD fulfill the transition at time 4. Through analyzing corresponding nodes' degrees, the stakeholders with strong risk-mitigating ability have larger contract price or more partners than others. Equation (8) shows that the risk-mitigating ability is only associated with risk-mitigating thresholds after recovering from risky state. In respect of risk-mitigating ability, it advocates the increase of partners' number to prevent the risk propagation. The property also explains why small-scale enterprise prefers to cooperate with large-scale enterprise to diminish risk.

From the comparison between (a-4) and (b-4) in Figure 10, it is found that stakeholders with strong risk-resisting ability include QI1, QI2, Sup2, Sup3, Sup4, Sup5, and Sup6. Equation (6) shows that a stakeholder's state depends upon three aspects: risk-resisting threshold; quantity of partners and their states. Nevertheless, stakeholders with strong riskresisting ability do not have high risk-resisting thresholds. The risk-resisting thresholds of them are smaller than PC and PCC. Their significant property is that there is only one partner cooperating with them. This is the reason why they are less likely to suffer economic loss. The stakeholders with high risk-resisting threshold, such as PC and PCC, are not affected until most of their partners are in risky state. 


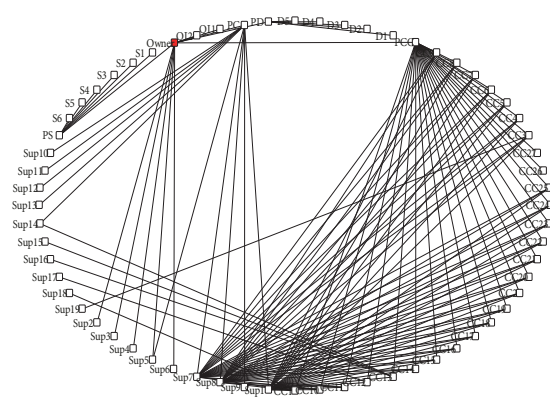

(a-1)

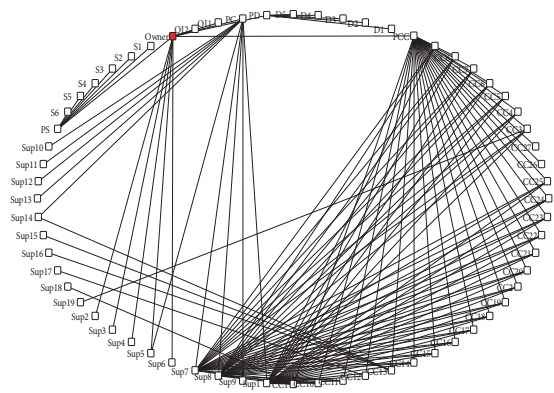

$(\mathrm{a}-2)$

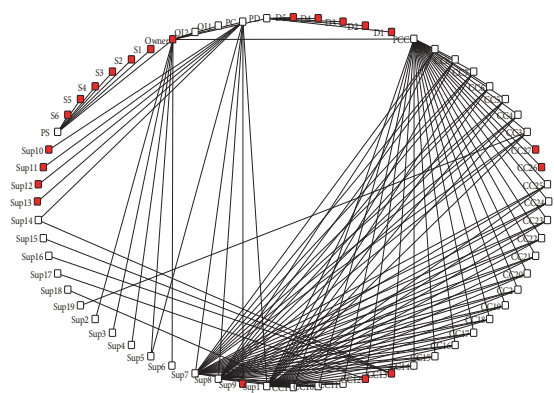

$(\mathrm{a}-3)$

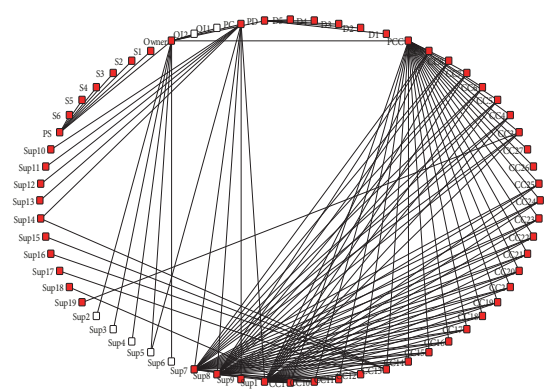

$(\mathrm{a}-4)$

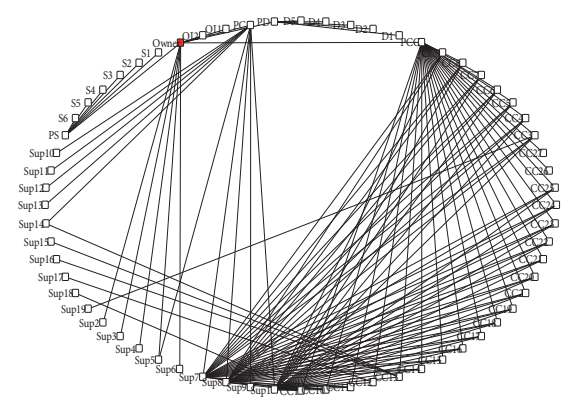

(b-1)

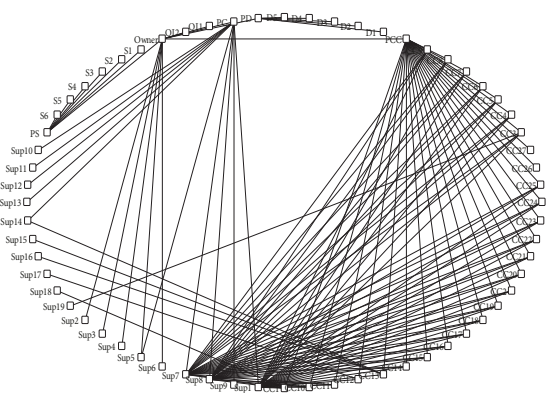

(b-2)

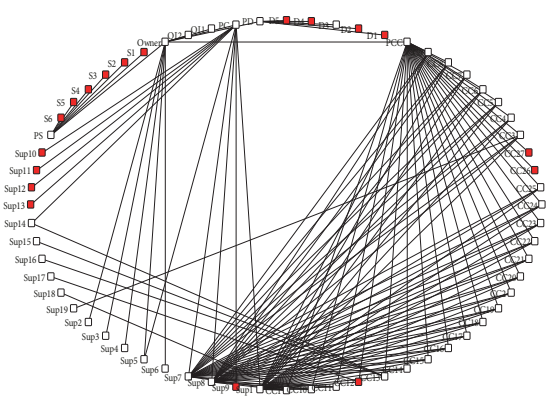

(b-3)

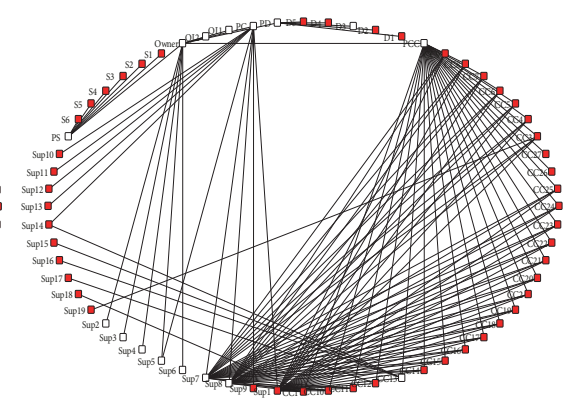

(b-4)

FIGURE 10: Variation process of number of loss-making stakeholders under situations with and without risk mitigation. Red nodes represent loss-making stakeholders and white nodes denote normal stakeholders. (a-1), (a-2), (a-3), and (a-4) show the diffusion process of delayed payment without risk mitigation from time 1 to 4 . (b-1), (b-2), (b-3), and (b-4) present the diffusion process of delayed payment with risk mitigation from time 1 to 4 .

Thus, prevention of risk propagation advocates the decrease of partners' number in respect of risk-resisting ability. In summary, the quantity of partners and contract price of a stakeholder are extremely critical to its economic state in the process of RPDP.
4.3. Comparison of Propagation Results of SNCPYHS and Random Stakeholder Network. To explore the property of SNCPYHS under the delay payments, we assume a random stakeholder network which has same stakeholders, but contract price among stakeholders is completely random. In 


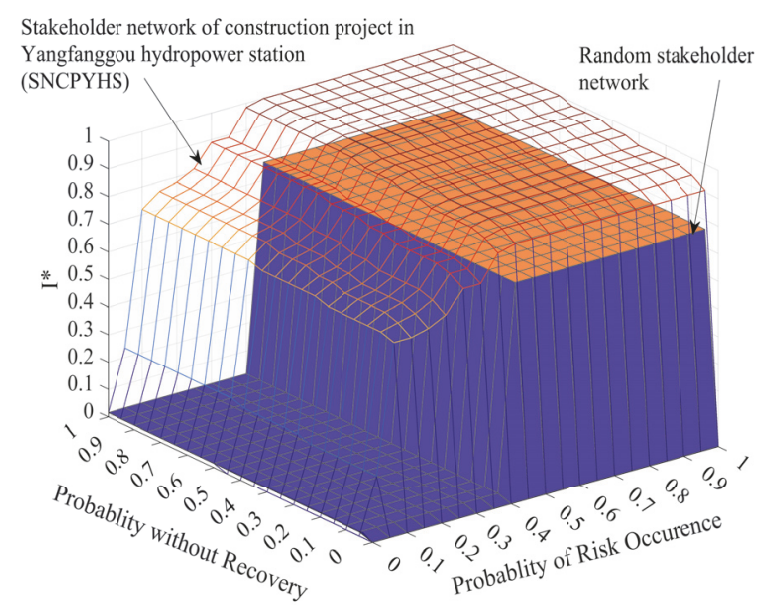

FIGURE 11: Variation of ultimate stable values $(I *)$ with simultaneous increases of probability without recovery and probability of risk occurrence in SNCPYHS and random stakeholder network. The $I *$ is an ultimate stable value of loss-making stakeholders proportion (I). Two probabilities simultaneously increase from 0 to 1 .

the random stakeholder network, the redistributed contract price can be set as $\widehat{w}_{i j}=w_{\min }+\left(w_{\max }-w_{\min }\right) \times \delta . \delta$ is a random variable following $[0,1]$ uniform distribution. The random numbers generated by MATLAB are provided in Supplementary Materials. Section 4.1 has proved that the value of $I$ will be stable at a fixed value $I *$. The robustness is an ability of the network to maintain final connectivity when a fraction of its nodes is damaged. It can be weighed by $I *$ [55]. Figure 11 displays the $I *$ values of two networks with increase of two risk probabilities at the growth rate 0.0500 when $t_{d}=1$.

The result obtained from above figure shows that the whole curved surface of SNCPYHS is above the curved surface of the random stakeholder network. All $I *$ values of SNCPYHS are bigger than $I *$ values of the random stakeholder network, no matter what the probabilities are. This means that the random stakeholder network has stronger robustness than SNCPYHS when the Owner delays the payment. To analyze this phenomenon, probability distribution of nodes' degrees in SNCPYHS is shown in Figure 12. We can find that nodes' degrees of SNCPYHS show extreme heterogeneity compared with probability distribution of nodes' degrees of random stakeholder network in Figure 13. The most of nodes' degrees are relatively small, but a few nodes' degrees are extremely large. Degrees of the Owner, PC, and PCC, for instance, are significantly higher than others'. That is to say, risk easily propagates in SNCPYHS when stakeholders with high node's degree, such as the Owner and Prime Contractor, delay the payment. The simulation result is consistent with the earlier conclusion that a network with heterogeneity property is extremely vulnerable when some critical nodes encounter failure [56].

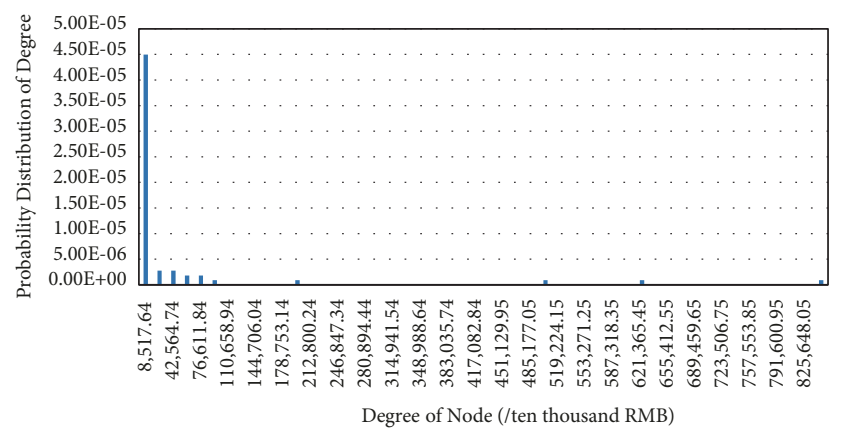

FIGURE 12: Probability distribution of nodes' degrees of stakeholder network of construction project in Yangfanggou hydropower station (SNCPYHS). As a node's degree is equal to the sum of contract prices owned by a stakeholder, probability distribution of nodes' degrees of SNCPYHS represents the probability distribution of contract prices of SNCPYHS.

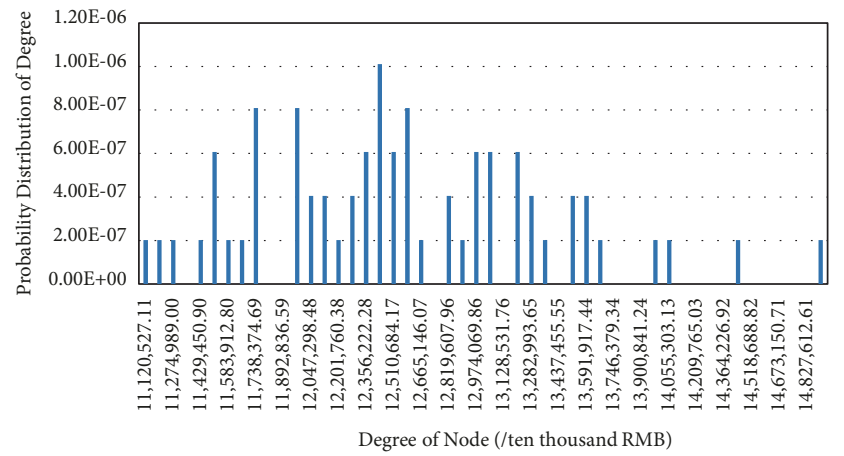

FIgURE 13: Probability distribution of nodes' degrees of random stakeholder network. As a node's degree is equal to the sum of contract prices owned by a stakeholder, probability distribution of nodes' degrees of the random stakeholder network represents the probability distribution of contract prices of the random stakeholder network.

\section{Conclusions}

This paper presents a new perspective to analyze the risk of delayed payment in LHPC. By comparing the previous studies in risk analysis, the dynamic properties of propagation and diffusion from one stakeholder to another are fully taken into account in risk of delayed payment. The relationships among stakeholders are viewed as complex network to present the pattern of loss diffusion in actual project. We collected all contract prices to build the stakeholder network of LHPC and established a CA-SIS-based model considering relevance between risk mitigation and time to approximate RPDP. Because of close correlation between stakeholder's status and importance in the whole project, a new threshold of risk mitigation was put forward to complete original propagation model. Subsequently, under delayed payment of the Owner in SNCPYHS, parameters of the model were varied to simulate the results of RPDP. The conclusions show the following: (1) decline of stable value $I *$ with the increase of $t_{d}$ and contrast between the model with and without risk mitigation prove the rationality and feasibility of the novel model; (2) 
regardless of change of parameters in the model, RPDP has three phases: (1) risk first slightly propagates, (2) risk then breaks out, and (3) in last phase value of $I$ will converge to a stable value $I *$. The impact of a stakeholder's risk-resisting ability on ultimate stable $I *$ is more sensitive than risk mitigation ability when probabilities of risk occurrence and mitigation vary from 0 to 1 ; (3) the stakeholders with strong risk-mitigating ability have more partners than others. The significant property of stakeholders with strong risk-resisting ability is that there is only one partner cooperating with them. Two important properties indicate that the quantity of a stakeholder's partners is extremely critical to its economic state in the process of RPDP; (4) the random stakeholder network has stronger robustness than SNCPYHS, showing that, because of heterogeneity of contract price distribution, risk easily propagates in SNCPYHS when some critical stakeholders delay the payment.

The conclusions above also provide theoretical basis for proactively controlling RPDP in the stakeholder network. For example, cooperating with several stakeholders could assist them to mitigate risk after suffering delayed payment. In addition, separating large contract price into numerous small contract prices can improve the homogeneity of contract price distribution. However, this suggestion increases the difficulty of risk resistance when the stakeholder's partners are all in risky state. Therefore, in the future research, more reasonable allocation of contract price is very essential and meaningful to provide an approach to solve the problem.

\section{Data Availability}

The whole adjacent matrix data used to support the findings of this study are included within the Supplementary Materials.

\section{Conflicts of Interest}

The authors declare that there are no conflicts of interest regarding the publication of this paper.

\section{Acknowledgments}

The authors would like to acknowledge the support of the National Natural Science Foundation of China (Grant no. 51779195).

\section{Supplementary Materials}

MATLAB simulation is used in the paper. In order to verify the authenticity of the research and present the results easily for readers, the data of the study and codes of MATLAB simulation are provided. "matrix.xls" presents the whole adjacent matrix data of the article. "RPDP_with_mitigation" and "RPDP_without_mitigation" show the results of RPDP with and without risk mitigation. "Proba_analysis" includes the results of RPDP under change of two kinds of probabilities. "SNCPYHS_random_network" compares the propagation results in SNCPYHS and random stakeholder network, and "Distribution_analysis" analyzes the property of
SNCPYHS. "Degree_Distribution" is a function calculating nodes' degrees. (Supplementary Materials)

\section{References}

[1] S. X. Zeng, H. Y. Ma, H. Lin, R. C. Zeng, and V. W. Y. Tam, "Social responsibility of major infrastructure projects in China," International Journal of Project Management, vol. 33, no. 3, pp. 537-548, 2015.

[2] H. Jiang, M. Qiang, and P. Lin, "Assessment of online public opinions on large infrastructure projects: A case study of the Three Gorges Project in China," Environmental Impact Assessment Review, vol. 61, pp. 38-51, 2016.

[3] L. Bing, R. L.-K. Tiong, W. W. Fan, and D. A.-S. Chew, "Risk management in international construction joint ventures," Journal of Construction Engineering and Management, vol. 125, no. 4, pp. 277-284, 1999.

[4] X. Zhang, "Financial viability analysis and capital structure optimization in privatized public infrastructure projects," Journal of Construction Engineering and Management, vol. 131, no. 6, pp. 656-668, 2005.

[5] A. A. G. Hassanein and H. M. F. Afify, "A risk identification procedure for construction contracts - A case study of power station projects in Egypt," Civil Engineering and Environmental Systems, vol. 24, no. 1, pp. 3-14, 2007.

[6] W. Tang, Z. Li, M. Qiang, S. Wang, and Y. Lu, "Risk management of hydropower development in China," Energy, vol. 60, pp. 316324, 2013.

[7] T. Ramachandra and J. O. B. Rotimi, "Causes of payment problems in the New Zealand construction industry," Construction Economics and Building, vol. 15, no. 1, pp. 43-55, 2015.

[8] . Antonio J, "Financial risks in construction projects," African Journal of Business Management, vol. 5, no. 31, 2011.

[9] D.-C. Wang and L.-C. Wang, "Using analytic network process to analyze problems for implementing turn-key construction projects in Taiwan," Journal of Central South University of Technology (English Edition), vol. 18, no. 2, pp. 558-567, 2011.

[10] A. Rostami and C. F. Oduoza, "Key risks in construction projects in Italy: Contractors' perspective," Engineering, Construction and Architectural Management, vol. 24, no. 3, pp. 451462, 2017.

[11] H.-L. Yang and C.-T. Chang, "A two-warehouse partial backlogging inventory model for deteriorating items with permissible delay in payment under inflation," Applied Mathematical Modelling: Simulation and Computation for Engineering and Environmental Systems, vol. 37, no. 5, pp. 2717-2726, 2013.

[12] H. Abdul-Rahman, M. Kho, and C. Wang, "Late payment and nonpayment encountered by contracting firms in a fastdeveloping economy," Journal of Professional Issues in Engineering Education and Practice, vol. 140, no. 2, 2014.

[13] P. X. W. Zou, G. Zhang, and J. Wang, "Understanding the key risks in construction projects in China," International Journal of Project Management, vol. 25, no. 6, pp. 601-614, 2007.

[14] X. Liu, Z. F. Wang, and D. Z. Jin, "Risk evaluation of cost for hydropower construction under risk fixed schedule probability using Monte Carlo simulation method," Technics Technologies Education Management-Ttem, vol. 6, no. 2, pp. 287-299, 2011.

[15] J.-L. Zhou, Z.-H. Bai, and Z.-Y. Sun, "A hybrid approach for safety assessment in high-risk hydropower-constructionproject work systems," Safety Science, vol. 64, pp. 163-172, 2014. 
[16] G.-F. Liu, X.-T. Feng, G.-L. Feng, B.-R. Chen, D.-F. Chen, and S.-Q. Duan, "A Method for Dynamic Risk Assessment and Management of Rockbursts in Drill and Blast Tunnels," Rock Mechanics and Rock Engineering, vol. 49, no. 8, pp. 3257-3279, 2016.

[17] Y. Bai, Z. Dai, and W. Zhu, "Multiphase risk-management method and its application in tunnel engineering," Natural Hazards Review, vol. 15, no. 2, pp. 140-149, 2014.

[18] D. M. Shalev and J. Tiran, "Condition-based fault tree analysis (CBFTA): a new method for improved fault tree analysis (FTA), reliability and safety calculations," Reliability Engineering \& System Safety, vol. 92, no. 9, pp. 1231-1241, 2007.

[19] N. Paltrinieri, F. Khan, P. Amyotte, and V. Cozzani, "Dynamic approach to risk management: Application to the Hoeganaes metal dust accidents," Process Safety and Environmental Protection, vol. 92, no. 6, pp. 669-679, 2014.

[20] F. Khan, S. J. Hashemi, N. Paltrinieri, P. Amyotte, V. Cozzani, and G. Reniers, "Dynamic risk management: a contemporary approach to process safety management," Current Opinion in Chemical Engineering, vol. 14, pp. 9-17, 2016.

[21] D. Baccarini, "The concept of project complexity-a review," International Journal of Project Management, vol. 14, no. 4, pp. 201-204, 1996.

[22] C. Fang, F. Marle, E. Zio, and J.-C. Bocquet, "Network theorybased analysis of risk interactions in large engineering projects," Reliability Engineering \& System Safety, vol. 106, pp. 1-10, 2012.

[23] J. Yang, G. Q. Shen, M. Ho, D. S. Drew, and X. Xue, "Stakeholder management in construction: An empirical study to address research gaps in previous studies," International Journal of Project Management, vol. 29, no. 7, pp. 900-910, 2011.

[24] R. J. Yang and P. X. W. Zou, "Stakeholder-associated risks and their interactions in complex green building projects: A social network model," Building and Environment, vol. 73, pp. 208222, 2014

[25] C. Z. Li, J. Hong, F. Xue, G. Q. Shen, X. Xu, and M. K. Mok, "Schedule risks in prefabrication housing production in Hong Kong: a social network analysis," Journal of Cleaner Production, vol. 134, pp. 482-494, 2016.

[26] X. Wang, N. Xia, Z. Zhang, C. Wu, and B. Liu, "Human safety risks and their interactions in China's subways: stakeholder perspectives," Journal of Management in Engineering, vol. 33, no. 5, Article ID 05017004, 2017.

[27] K. Y. Mok, G. Q. Shen, R. J. Yang, and C. Z. Li, "Investigating key challenges in major public engineering projects by a networktheory based analysis of stakeholder concerns: A case study," International Journal of Project Management, vol. 35, no. 1, pp. 78-94, 2017.

[28] T. Yu, G. Q. Shen, Q. Shi, X. Lai, C. Z. Li, and K. Xu, "Managing social risks at the housing demolition stage of urban redevelopment projects: A stakeholder-oriented study using social network analysis," International Journal of Project Management, vol. 35, no. 6, pp. 925-941, 2017.

[29] A. S. Deshpande, O. M. Salem, and R. A. Miller, "Analysis of the higher-order partial correlation between CII best practices and performance of the design phase in fast-track industrial projects," Journal of Construction Engineering and Management, vol. 138, no. 6, pp. 716-724, 2012.

[30] N. Massoud, A. Saunders, and B. Scholnick, "The cost of being late? The case of credit card penalty fees," Journal of Financial Stability, vol. 7, no. 2, pp. 49-59, 2011.

[31] I. Eusgeld, W. Kröger, G. Sansavini, M. Schläpfer, and E. Zio, "The role of network theory and object-oriented modeling within a framework for the vulnerability analysis of critical infrastructures," Reliability Engineering \& System Safety, vol. 94, no. 5, pp. 954-963, 2009.

[32] C. M. Rocco S. and J. Emmanuel Ramirez-Marquez, "Identification of top contributors to system vulnerability via an ordinal optimization based method," Reliability Engineering \& System Safety, vol. 114, no. 1, pp. 92-98, 2013.

[33] R. Carvalho, L. Buzna, F. Bono, E. Gutiérrez, W. Just, and D. Arrowsmith, "Robustness of trans-European gas networks," Physical Review E: Statistical, Nonlinear, and Soft Matter Physics, vol. 80, no. 1, Article ID 016106, 2009.

[34] B. Wu, A. Tang, and J. Wu, "Modeling cascading failures in interdependent infrastructures under terrorist attacks," Reliability Engineering \& System Safety, vol. 147, pp. 1-8, 2016.

[35] J. M. Torres, K. Brumbelow, and S. D. Guikema, "Risk classification and uncertainty propagation for virtual water distribution systems," Reliability Engineering \& System Safety, vol. 94, no. 8, pp. 1259-1273, 2009.

[36] X. Xu, J. Hu, F. Liu, and L. Liu, "Scaling and correlations in three bus-transport networks of China," Physica A: Statistical Mechanics and its Applications, vol. 374, no. 1, pp. 441-448, 2007.

[37] H. Han and R. Yang, "Improvement on load-induced cascading failure in asymmetrical interdependent networks: modeling and analysis," Mathematical Problems in Engineering, Art. ID 194568, 10 pages, 2015.

[38] W. O. Kermack and A. G. McKendrick, "Contributions to the mathematical theory of epidemics-I," Bulletin of Mathematical Biology, vol. 53, no. 1-2, pp. 33-55, 1991.

[39] R. Pastor-Satorras and A. Vespignani, "Epidemic spreading in scale-free networks," Physical Review Letters, vol. 86, no. 14, pp. 3200-3203, 2001.

[40] C. Moore and M. E. J. Newman, "Epidemics and percolation in small-world networks," Physical Review E-Statistical Physics, Plasmas, Fluids, and Related Interdisciplinary Topics, vol. 61, no. 5B, pp. 5678-5682, 2000.

[41] G. Yan, Z. Fu, J. Ren, and W. Wang, "Collective synchronization induced by epidemic dynamics on complex networks with communities," Physical Review E: Statistical, Nonlinear, and Soft Matter Physics, vol. 75, no. 1, Article ID 016108, 2007.

[42] L.-L. Xia, G.-P. Jiang, B. Song, and Y.-R. Song, "Rumor spreading model considering hesitating mechanism in complex social networks," Physica A: Statistical Mechanics and its Applications, vol. 437, pp. 295-303, 2015.

[43] Z. Wang, H. Yao, G. L. Yang, and J. Du, "Failure risk propagation and protection schemes in coupled systems," Chaos Solitons \& Fractals, vol. 80, pp. 62-75, 2015.

[44] V. M. Eguíluz and K. Klemm, "Epidemic threshold in structured scale-free networks," Physical Review Letters, vol. 89, no. 10, Article ID 108701, 2002.

[45] Z. H. Liu and B. B. Hu, "Epidemic spreading in community networks," Europhysics Letters, vol. 72, no. 2, pp. 315-321, 2005.

[46] S. K. Ansah, "Causes and effects of delayed payments by clients on construction projects in Ghana," Journal of Construction Project Management and Innovation, vol. 1, no. 1, pp. 27-45, 2011.

[47] M. Francis, T. Ramachandra, and J. O. B. Rotimi, "Strategies to minimise the effects of delayed payments," Proceedings of the Institution of Civil Engineers-Management Procurement and Law, vol. 169, no. 5, pp. 199-207, 2016.

[48] N. Boccara and K. Cheong, "Critical behaviour of a probabilistic automata network SIS model for the spread of an infectious disease in a population of moving individuals," Journal of 
Physics A: Mathematical and General, vol. 26, no. 15, pp. 37073717, 1993.

[49] A. Lisnianski, "Estimation of boundary points for continuumstate system reliability measures," Reliability Engineering \& System Safety, vol. 74, no. 1, pp. 81-88, 2001.

[50] K. Kolowrocki, "On limit reliability functions of large multistate systems with ageing components," Applied Mathematics and Computation, vol. 121, no. 2-3, pp. 313-361, 2001.

[51] A. Chandrakar, A. K. Nayak, and G. Vinod, "Reliability analysis of process controlled systems considering dynamic failure of components," International Journal of System Assurance Engineering and Management, vol. 6, no. 2, pp. 93-102, 2015.

[52] Y. L. Zhang and N. D. Yang, "Research on robustness of RD network under cascading propagation of risk with gray attack information," Reliability Engineering \& System Safety, vol. 117, pp. 1-8, 2013.

[53] F. Wang, X.-Z. Zheng, S. Chen, and J.-L. Zhou, "Emergency repair scope partition of city water distribution network: a novel approach considering the node importance," Water Resources Management, vol. 31, no. 12, pp. 3779-3794, 2017.

[54] Y. Zhang and N. Yang, "Development of a mitigation strategy against the cascading propagation of risk," in in RD network, vol. 68, pp. 161-168, Safety Science, 2014.

[55] J. Li, J. Wu, Y. Li, H.-Z. Deng, and Y.-J. Tan, "Attack robustness of scale-free networks based on grey information," Chinese Physics Letters, vol. 28, no. 5, Article ID 058904, 2011.

[56] R. Albert, H. Jeong, and A.-L. Barabási, "Error and attack tolerance of complex networks," Nature, vol. 406, no. 6794, pp. 378-382, 2000. 


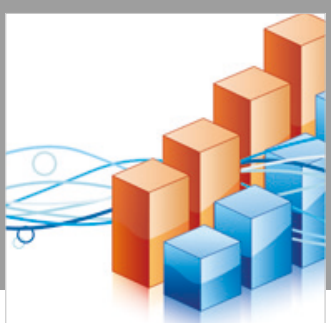

Advances in

Operations Research

\section{-n-m}
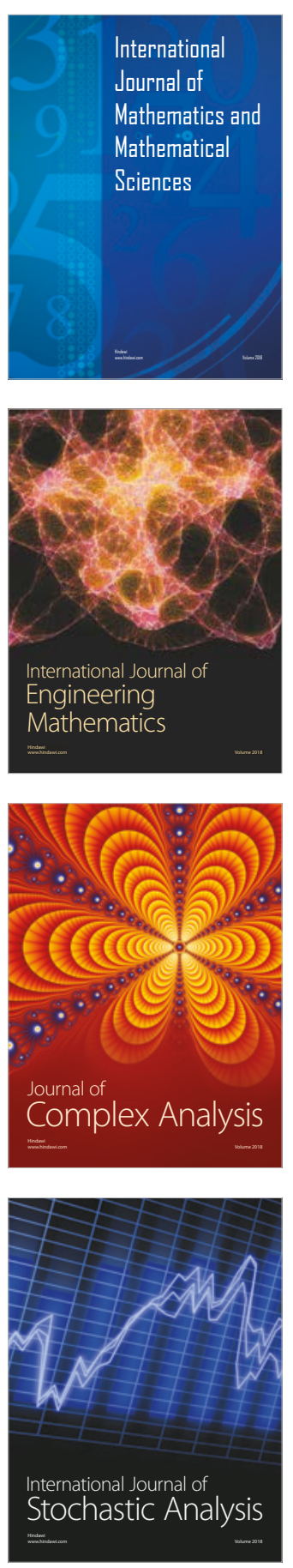
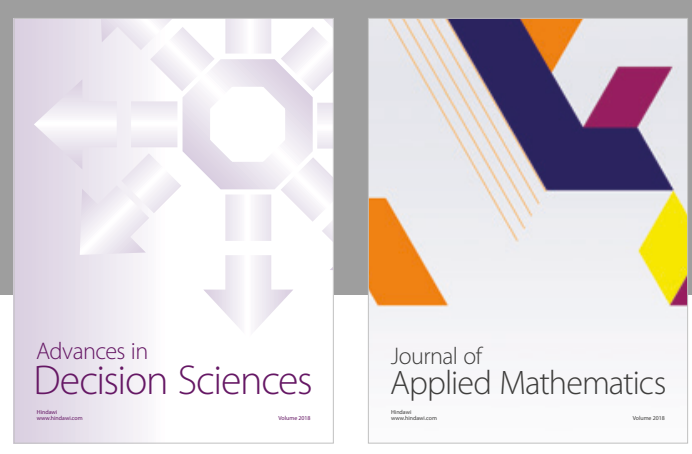

Journal of

Applied Mathematics
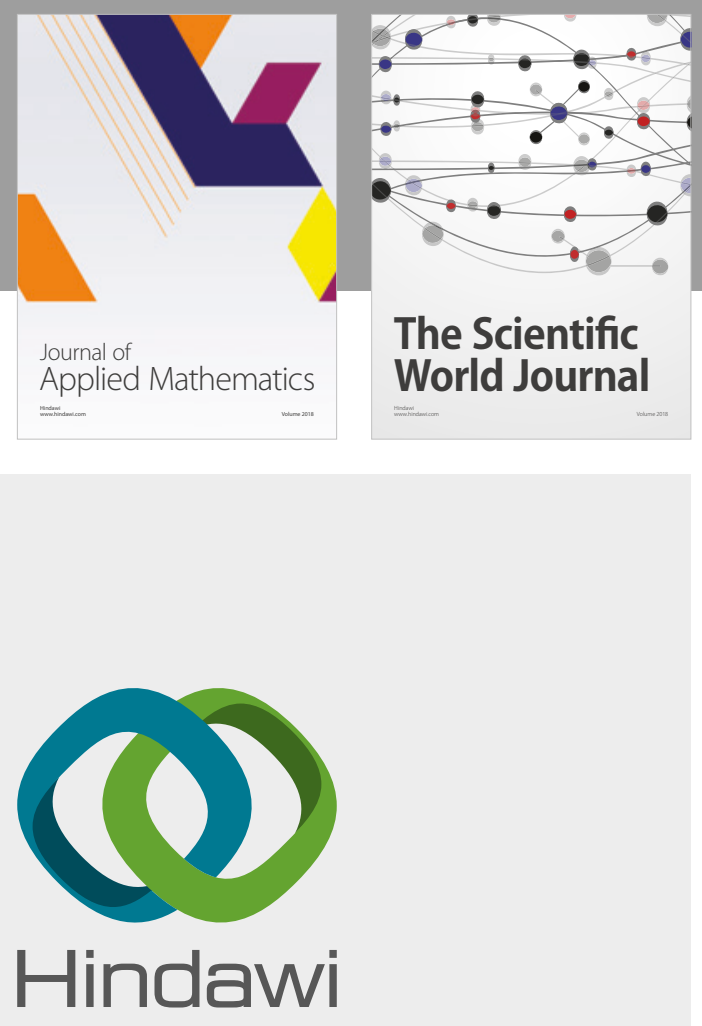

Submit your manuscripts at

www.hindawi.com

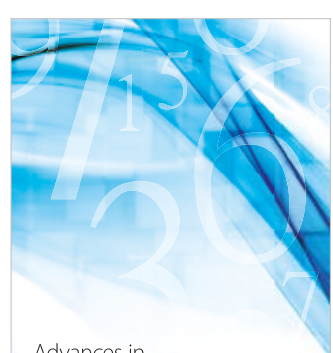

Advances in
Numerical Analysis
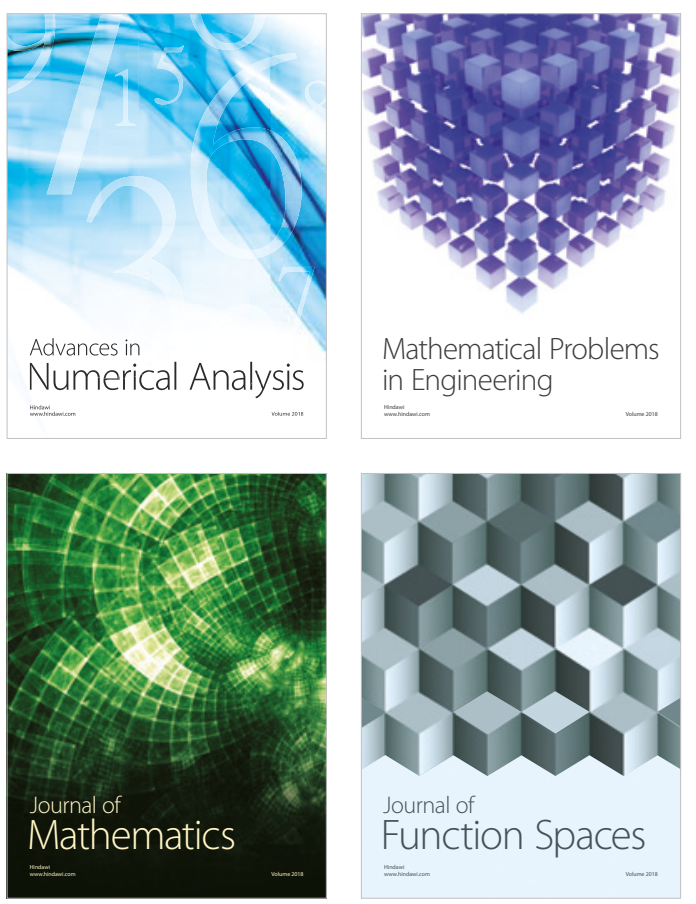

Mathematical Problems in Engineering

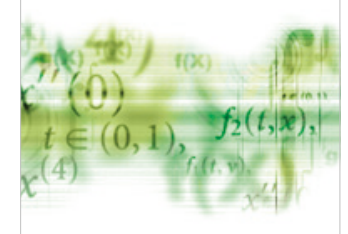

International Journal of

Differential Equations

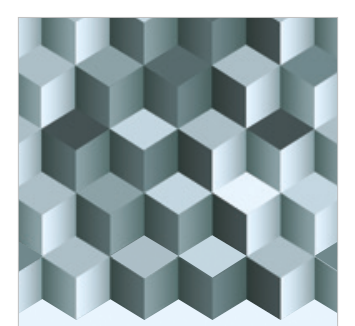

Journal of

Function Spaces

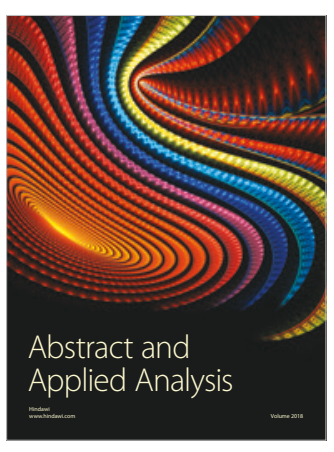

The Scientific

World Journal

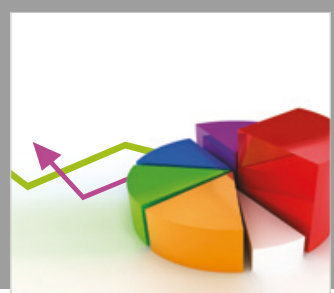

Journal of

Probability and Statistics
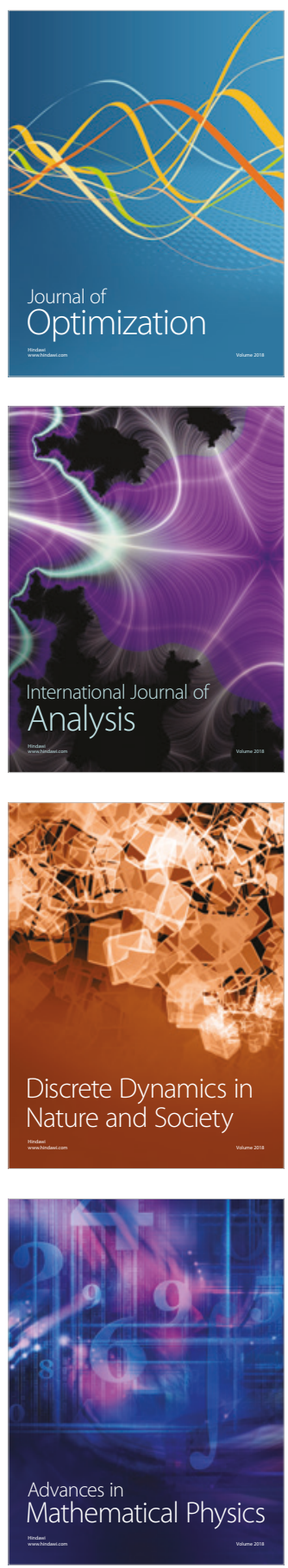